\title{
Transculturación y latinoamericanismo
}

\author{
Transculturation and Latin Americanism \\ Transculturação e latinoamericanismo
}

\section{Mabel Moraña}

WASHINGTON UNIVERSITY IN SAINT LOUIS, ESTADOS UNIDOS

Profesora del Department of Romance Languages and Literatures en Washington University, en Saint Louis, Estados Unidos. PhD por la University of Minnesota. Ha sido profesora en University of Pittsburgh, University of Southern California y University of Washington, Seattle. Entre sus últimas publicaciones se encuentran Arguedas / Vargas Llosa. Dilemas y ensamblajes (IberoamericanaVervuert, 2013), La escritura del límite (Iberoamericana-Vervuert, 2010), Crítica impura (Iberoamericana-Vervuert, 2004), Viaje al silencio. Exploraciones del discurso barroco (Iberoamericana-Vervuert, 1999) y Políticas de la escritura en América Latina (eXcultura, 1997). Ha editado y coeditado más de 30 libros, entre ellos Coloniality at Large. Latin America and the Postcolonial Debate (Duke University Press, 2008; con Enrique Dussel y Carlos A. Jauregui), El salto de Minerva. Género, intelectuales y poder en América Latina (Iberoamericana-Vervuert 2006; con María Rosa OliveraWilliams). Correo electrónico: mmorana@wustl.edu

\footnotetext{
Artículo de reflexión

Documento accesible en línea desde la siguiente dirección: http://revistas.javeriana.edu.co doi:10.11144/Javeriana.cl21-41.trla
} 


\section{Resumen}

Este artículo analiza el papel que ha jugado la teoría de la transculturación en los campos de las ciencias sociales y de los estudios humanísticos referidos a América Latina. El texto realiza un resumido recuento de las distintas etapas de elaboración del concepto y su funcionalidad en debates actuales marcados por los conceptos y las experiencias de la migración, la fragmentación social, etc. Además, se pregunta sobre la utilidad de la elaboración sobre la transculturación en los escenarios de la postmodernidad.

Palabras clave: Ángel Rama; contrapunteo; Fernando Ortiz; diferencia; ciudad letrada; Picón Salas; estudios culturales; Bourdieu; Foucault

\section{Abstract}

This article analyzes the role played by the transculturation theory on social sciences and humanistic studies related to Latin America. This text summarizes the different elaboration stages of the concept and its functionality in current debates marked by the concepts and experiences of migration, social fragmentation, etc.

Additionally, we question the usefulness of the elaboration on transculturation in postmodern scenarios.

Keywords: Angel Rama; comparison; Fernando Ortiz; different; literate city; Picon Salas; cultural studies; Bourdieu; Foucault

\section{Resumo}

Este artigo analisa o papel jogado pela teoria da transculturação nos campos das ciências sociais e dos estudos humanísticos referidos a América Latina. $\mathrm{O}$ texto realiza um reconto breve dos vários estágios na elaboração do conceito e sua funcionalidade em debates atuais marcados pelos conceitos e experiências da migração, a fragmentação social, etc. Além disso, se questiona pela utilidade da elaboração sobre a transculturação em cenários da pós-modernidade.

Palavras-chave: Ángel Rama; contraponto; Fernando Ortiz; diferença; cidade letrada; Picón Salas; estudos culturais; Bourdieu; Foucault 
REFERIRSE HOY EN día a la teoría de la transculturación y vincularla, específicamente, al campo transnacionalizado del latinoamericanismo, requiere ajustes sustanciales. Después de todo, la teoría de la transculturación, si atendemos a la más recibida genealogía que ubica su origen en el Contrapunteo del tabaco y el azúcar $(1940,1978)$ de Fernando Ortiz, tiene a esta altura más de setenta años. Más de treinta han pasado desde su reformulación crítico-literaria por parte de Ángel Rama, periodo en el que se registran algunos de los cambios más profundos de la historia cultural de Occidente. Estos se manifiestan en América Latina con hondas transformaciones sociales y políticas que se acentúan notoriamente a partir del fin de la Guerra Fría. Entre ellas debe enfatizarse el desmantelamiento de los movimientos de liberación nacional y el debilitamiento de la izquierda setentista que sería sucedida por los regímenes de la así llamada marea rosada; el resurgimiento de diversas variantes del populismo; el efecto arrasador del neoliberalismo; el incremento de la migración, y la prominencia de la cultura audiovisual, la industria cultural y la digitalización en desmedro de la centralidad letrado-escrituraria desde la que Ángel Rama formulara sus propuestas. Aunque el valor crítico-teórico de la teoría de la transculturación es indudable para el estudio de las tensiones, conflictos y estrategias de la modernidad, más discutible resulta su rendimiento teórico en los escenarios postmodernos, marcados por las dinámicas globalizadoras, así como por el debilitamiento de las culturas nacionales y los avances acelerados de la mercantilización cultural. En cualquier caso, conviene repasar críticamente el contenido de la propuesta transculturadora para después analizar algunas de sus proyecciones principales.

En primer lugar, como es sabido, la teoría de la transculturación resulta inseparable de otras teorizaciones que se desarrollan en América Latina de forma paralela en torno a las nociones de antropofagia, heterogeneidad, hibridez, colonialidad del poder y transmodernidad; nociones todas que apuntan a la crítica de las culturas nacionales y de la modernidad, que enmarcara el surgimiento de estas como parte del proyecto continental de establecimiento y consolidación de la república criolla (Schmidt-Welle, "¿ititeraturas heterogéneas o literatura de la transculturación?"; Antonio Cornejo Polar). Los conceptos mencionados remiten, con distintos matices, a la problemática inserción de América Latina en el espacio civilizatorio del occidentalismo; proceso que conlleva la combinatoria compleja del producto simbólico (y de la cultura material correspondiente) proveniente de los centros del capitalismo, con el sustrato vernáculo que se manifiesta de manera más clara en las que Rama llama las culturas interiores de América Latina. En otras partes me he 
referido a los objetivos más salientes del reciclaje crítico literario que Rama efectúa de la noción de transculturación, la cual tuvo en la obra de Ortiz su versión inicial antropológico-cultural y en De la conquista a la independencia (1944) de Mariano Picón Salas su más extensiva aplicación historicista. La reelaboración de Rama surge como exploración de los límites y de la permeabilidad de las culturas nacionales, y como indagación de los alcances de la transitividad cultural que, de centro a periferia, transmitía los valores y estrategias representacionales de la modernidad en espacios autóctonos. Las dinámicas transculturadoras dan como resultado, como es sabido, procesos de hibridación simbólica que afectan la selección temática al igual que los usos de la lengua y los recursos de estructuración discursiva a nivel literario. El deslumbramiento de Rama por la descollante literatura de José María Arguedas, cataliza el proyecto de desarrollo de la teoría de la transculturación narrativa que, superando las interpretaciones previsibles de la estética del regionalismo, alcanza en la producción literaria de la que Rama denomina el "área cultural andina" uno de sus momentos más innovadores y paradigmáticos.

En segundo lugar, debe mencionarse asimismo la utilización del concepto de transculturación como herramienta ordenadora del archivo criollo; es decir, como concepto articulador de la producción letrada latinoamericana y de sus vínculos con lo que más ampliamente autores como Pascale Casanova y Franco Moretti han denominado "la república mundial de las letras". Ante la pulsión homogeneizante de la modernización, Rama explora el estatuto variable de lo popular; asiento de una indómita heterogeneidad pluricultural que revela la naturaleza neocolonial y dependiente de América Latina, así como las especificidades de su articulación con la oferta simbólica proveniente de los centros europeos y norteamericanos, la cual incluye sobre todo técnicas de representación vinculadas con el cine, las particularidades lingüísticas y temáticas, etc. Es justamente en el espacio de lo popular (tanto en sus modalidades regionales como en el cosmopolitismo ciudadano) en donde se definen formas de subjetividad y conciencia social que requieren estrategias representacionales específicas, abiertas a la impureza de una modernidad que se superpone a las matrices originarias de lo autóctono, lo pre-moderno, lo rural, etc. Estos sustratos revelan, a pesar de su fuerte enclave tradicionalista y de su preferencia por las formas locales, los impulsos transnacionalizados que contaminan lo vernáculo y que hacen de lo nacional una categoría fluida e inestable, atravesada por el conflicto intercultural y por la tensa relación que hay entre localidad y globalidad; entre regionalismo y modernización. 
De esta manera, si en Fernando Ortiz el concepto de transculturación había servido para teorizar etnográficamente los conflictos inherentes a la aplicación del proceso de modernización en áreas periféricas a partir de la dramatización alegórica de espacios simbólicos contrapuestos, en Mariano Picón Salas el modelo transculturador es utilizado como punto de partida para la construcción de un paradigma historiográfico que adquiere en la versión de Rama una tonalidad decididamente culturalista que, liberada del economicismo, se inclina hacia un análisis del modelo simbólico de intercambios, traducción y reciclaje cultural. La versión de Rama provee así un eje conceptual en torno al que se organiza la interpretación de los intercambios culturales que se producen en la modernidad del centro al margen, siguiendo los principios de la teoría difusionista en boga en los años 7o, según la cual los núcleos civilizadores diseminan modelos cognitivos, categorías y valores en sus áreas de influencia, con impulsos que remedan las dinámicas del colonialismo. La agencia letrada y el campo escriturario son los espacios en los que se fraguan las estrategias legitimadoras y las prácticas representacionales que la ciudad letrada ordenará a partir de complejos procesos de institucionalización cultural. La mecánica de los procesos transculturadores presentados por Picón Salas se resume en las fórmulas de la mestización cultural. Indica así el historiador venezolano, cuáles son los factores y resultados de la articulación de lo foráneo y lo vernáculo:

Las formas de la cultura europea penetran desde el comienzo en los centros urbanos que se fundan en América en el siglo XVI, aunque la originalidad del ambiente impone ... el precoz aparecimiento de formas mestizas (69, énfasis del autor).

Para Picón Salas la transculturación constituye una cualidad identitaria históricamente constituida a partir de los procesos sincréticos que se originaron en el colonialismo. En la versión del crítico uruguayo, el proceso es pensado con más énfasis en la negociación bilateral por la cual el resultado final no se reduce a la mera suma de las partes que lo componen, ya que a partir de la combinación de elementos foráneos y vernáculos surgen propuestas estético-ideológicas complejas que, a la vez que expresan dimensiones locales, se proyectan hacia espacios mayores, abiertos a los flujos e hibridaciones de la modernidad. Lo que en el venezolano alcanza tanto al sustrato de culturas indígenas como a las matrices culturales de judíos, franceses, anglosajones, chinos, etc., que se entronizan a partir de la inmigración en el desarrollo de la cultura cubana, en Rama se concentra en los procesos euro y anglo-céntricos correlativos a la implantación de la modernización en las culturas nacionales de 
América Latina. En Transculturación narrativa $(1974,1982)$ Rama desarrolla los términos presentes en la cita de Picón Salas, dando al modelo transculturador su encarnadura literaria precisa, a partir de la interpretación de lo vernáculo y del impacto que las nuevas tecnologías representacionales tienen en la obra de autores paradigmáticos como Rulfo, Asturias y, sobre todo, Arguedas. El modelo sirve a Rama para explicar, no solo la relación cultural que hay entre impulsos internacionales y culturas nacionales, sino también la relación que existe entre la centralización urbana y las culturas regionales, más cercanas a tradiciones y temáticas específicas vinculadas a contenidos ancestrales, vernáculos, rurales, míticos, etc.

El impacto de la teoría de la transculturación sobre el latinoamericanismo ha sido notorio y se ha extendido más allá del campo estrictamente literario, como modelo para la interpretación de relaciones interculturales, y de procesos de transmisión/ traducción cultural y de diseminación/resistencia a la penetración cultural en distintos registros. Dicho impacto no solo se articula con las elaboraciones de Foucault sobre los vínculos tensos que persisten entre el poder y el saber sino, asimismo, con las observaciones de Benjamin sobre la modernidad; con estudios sobre la cultura de la copia en áreas periféricas, y en general con los copiosos trabajos sobre cultura nacional, modernidad y occidentalismo que ocupan buena parte de la crítica de la cultura en América Latina desde los años 70 hasta la actualidad. La idea de la transculturación se vincula, en este sentido, con la agenda principal de los estudios culturales, con el pensamiento postcolonial, con los debates sobre postmodernidad, integración y relaciones interculturales, etc. Considerado retrospectivamente como un "etnógrafo posmoderno avant la lettre" (Coronil), Fernando Ortiz ha sido particularmente valorado por su capacidad de haber captado la fluidez e inestabilidad de los bordes que separan y conectan culturas, sociedades, proyectos y campos disciplinarios. Para Fernando Coronil, Ortiz ve las fronteras culturales como artificios de poder trazados precariamente sobre la arena de la historia, o sea como formas fluctuantes y provisionales, sujetas al cambio y a la negociación permanente; sometidas a procesos creativos de construcción y de deconstrucción que no permiten fosilizar ni la producción simbólica ni la subjetividad de la que surgen.

En un libro reciente titulado Bourdieu en la periferia (2014) he analizado las relaciones que el modelo formulado por Rama tiene con las nociones de campo cultural, 'habitus' y capital simbólico de Pierre Bourdieu. Indico allí que:

Con una mirada todavía influida por la teoría de la dependencia, el concepto de transculturación se plantea como una perspectiva transdisciplinaria que se acerca a la producción literaria desde la antropología, la historia, la lingüística, conectando los campos culturales y observando las movilizaciones transatlán- 
ticas y transnacionales de capital simbólico en momentos en que la categoría y la existencia histórica misma de las culturas nacionales se desestabiliza por efectos del autoritarismo y de crisis más amplias en el seno del capitalismo mundial. El estudio de Rama problematiza así lo nacional como matriz burguesa y liberal, mostrando los pliegues y fragmentos que componen el bricolage de la cultura. Sin embargo, el modelo transculturado, como el que ilustra luego La ciudad letrada (1984) en su propio registro, se atiene a los parámetros letrados, urbanistas, institucionalizados, patriarcales y occidentalistas, sin desafiarlos ni desestabilizar su primacía. En ese sentido, el modelo constituye una imprescindible descripción, aunque necesariamente parcial, del funcionamiento del proyecto moderno en áreas periféricas, agregando a los paradigmas de Bourdieu una perspectiva desde los márgenes de los grandes centros de producción capitalista. (Moraña 92-94)

La transculturación enfoca así uno de los temas neurálgicos de la modernidad periférica: el que se refiere a las negociaciones, empréstitos y reciclajes de material simbólico en espacios culturales que todavía conservan su especificidad y su diferencia; es decir, que escapan todavía a los influjos globalizadores cuya fuerza de arrasamiento y homogeneización es incalculablemente más fuerte que la de la modernidad de mediados del siglo pasado. Según algunos críticos como Alberto Moreiras (2001) sería justamente la obra de Arguedas, principalmente El zorro de arriba y el zorro de abajo (1990), la que con más fuerza daría por tierra con el modelo transculturador al demostrar, con la desarticulación radical del discurso letrado, el vaciamiento del lenguaje; la fragmentación del mundo ficcional, y la mise en abyme de la función autorial: el fracaso de las combinatorias que imponen, desde los centros, los impulsos transformadores que desnaturalizan lo local y enloquecen el mundo de los significados. El suicidio de Arguedas sería, en este sentido, una alegoría del fracaso de la modernidad y una impugnación radical de sus principios civilizadores. Al pasar del nivel ficcional al biográfico, y de este a los registros social, histórico e ideológico del Perú de finales de los 6o, los Zorros constituirían un testimonio inapelable de la perversidad de una modernidad excluyente que, sobreimpuesta desde la colonia sobre comunidades, culturas, lenguas e imaginarios colectivos, deja como saldo la devastación de lo autóctono y el vampirismo del gran capital que arrasa con valores, principios y proyectos sociales.

La utopía de la conciliación, el progreso y la mestización armónica llega a su fin cuando se impone la irracionalidad de la modernidad capitalista de la que habla Bolívar Echeverría, al sugerir que otras formas de modernidad 
son posibles en las afueras de la gran narrativa de la globalidad. En la misma dirección, el sociólogo portugués Boaventura de Sousa Santos se refiere a la necesidad de condenar el epistemicidio de la modernidad y la urgencia por desarrollar una ecología de los saberes que permita salvar aquellas formas de conocimiento del mundo que fueron desautorizadas -invisibilizadas, deslegitimadas- por la modernidad, que en sus impulsos transculturadores sobreimpuso, con la fuerza del neocolonialismo cultural, 'regímenes de verdad' (Foucault) que naturalizaron la exclusión desde las posiciones de poder de los grandes centros civilizatorios de Occidente.

En este sentido, la preocupación no es ya comprender la forma en que los avances de los centros repercuten en los márgenes o en las periferias de los grandes sistemas, sino explorar formas otras de interpretación y representación que permitan el reconocimiento de alteridades epistémicas y sus correspondientes registros simbólicos. Estas posiciones, que tienen en común su orientación hacia horizontes descolonizadores, ven en la transculturación una etapa anterior y superada de interculturalidad, que la globalización está volviendo obsoleta de modo acelerado. En la medida en que planteamientos dualistas del tipo Norte/Sur, Este/Oeste, centro/periferia pierden progresivamente vigencia y debilitan su rendimiento teórico, categorías basadas en el reconocimiento nítido de formas culturales foráneas y vernáculas van perdiendo sentido. En las nuevas combinatorias simbólicas de nuestro tiempo, las matrices originarias, locales, autóctonas o 'interiores', como las llamaba Rama, son cada vez menos visibles, y los modelos prominentes impuestos por la lógica de mercado y por el nomadismo simbólico parecen invadir los imaginarios y los modelos representacionales. La diferencia entre lo originario y lo exterior, en la que se apoyaba la teoría de la transculturación, se asocia hoy en día con las ideas de simulacro, collage, diversidad, sincretismo, copia, etc. La noción de fragmentación - contra la que se opone la intención totalizadora de la elaboración de Rama - ha sido romantizada como una forma nueva, innovadora, de rebeldía contracultural a través de la que se expresarían contenidos que se resisten a ser absorbidos en contextos mayores. En esta coyuntura, el latinoamericanismo se enfrenta al desafío de crear nuevas categorías para pensar la interculturalidad, la cual constituye un tema urgente, vinculado a la problemática vasta y compleja de la migración y a las nuevas formas de producción y de circulación cultural de nuestro tiempo; fenómenos que dan nuevo sentido a la noción de capital simbólico y cargan de significados inéditos las ideas de frontera, localidad, agencia y subjetividad colectiva, que parecen más idóneas para hacer referencia 
a procesos de extrema integración y, al mismo tiempo, a las nuevas formas de marginalidad y hegemonía que proliferan en contextos globales.

\section{Obras citadas}

Arguedas, José María. El zorro de arriba y el zorro de abajo.

Nanterre: Editorial Archivos, 1990. Impreso.

Casanova, Pascale. La república mundial de las letras.

Barcelona: Anagrama, 2001. Impreso.

Coronil, Fernando. "Introduction. Transculturation and the politics of theory.

Countering the center, Cuban counterpoint". Cuban counterpoint. Tobacco and

sugar. A. Fernando Ortiz. Durham: Duke University Press, 1995. Ix-lxi. Impreso.

De Sousa Santos, Boaventura. Una epistemología del Sur. La reinvención del conocimiento y la emancipación social. México: CLACSO y Siglo XXI, 2009. Impreso.

Moraña, Mabel. Bourdieu en la periferia. Santiago de Chile: Cuarto Propio, 2014. Impreso.

Moreiras, Alberto. The exhaustion of difference: the politics of Latin American cultural studies. Durham: Duke University Press, 2001. Impreso.

Moretti, Franco. Modern epic. The world-system from Goethe to García Márquez. Londres: Verso, 1996. Impreso. Ortiz, Fernando. Contrapunteo cubano del tabaco y el azúcar. Caracas: Biblioteca Ayacucho, 1978. Impreso.

Picón Salas, Mariano. De la conquista a la independencia. México: Fondo de Cultura Económica, 1944. Impreso.

Rama, Ángel. Transculturación narrativa en América Latina. México: Siglo XXI, 1982. Impreso.

Rama, Ángel. La ciudad letrada. Hanover: Ediciones del Norte, 1984. Impreso.

Schmidt-Welle, Friedhelm. " ¿Literaturas heterogéneas o literatura de la transculturación?". Asedios a la heterogeneidad cultural. Libro de homenaje a Antonio Cornejo Polar. Coords. José Antonio Mazzotti y U. Juan Zevallos Aguilar. Philadelphia: Asociación Internacional de Peruanistas, 1996. 37-45. Impreso.

Schmidt-Welle, Friedhelm, ed. Antonio Cornejo Polar y los estudios latinoamericanos. Pittsburgh: Instituto Internacional de Literatura Iberoamericana y Ibero-Amerikanisches Institut, 2002. Impreso. 


\section{Comentario de Vittoria Borsò}

(UNIVERSIDAD HEINRICH HEINE, DÜSSELDORF)

COMO UNA DE las autoras más influyentes, Mabel Moraña exploró la productividad transcultural del barroco novohispano. ${ }^{1}$ En este ensayo vuelve al concepto de transculturación desde la crítica actual de la modernidad frente a las crisis del hipercapitalismo global. Su análisis desemboca en la tesis de que el concepto de transculturación ya no vale para analizar las dinámicas globalizadoras actuales, que conllevan el debilitamiento de las culturas nacionales y los avances acelerados de la mercantilización cultural. Transculturación corresponde, así reza el claro veredicto, a una etapa anterior de los procesos culturales; una etapa que la globalización hace obsoleta.

Transculturación, así como acepciones afines tales como antropofagia, heterogeneidad, hibridez y colonialidad del poder, remiten a la problemática inserción de América Latina al espacio civilizatorio del occidentalismo. Lo demuestra, según Moraña, la dramatización alegórica de espacios simbólicos contrapuestos en el concepto de Contrapunteo del tabaco y del azúcar (Fernando Ortiz), o el colonialismo sincrético en el origen -abierto a los flujos e hibridaciones de la modernidad según Mariano Picón Sala (De la conquista a la independencia) - cuyo punto de partida es el paradigma historiográfico de combinación de elementos foráneos y vernáculos. También en la transculturación narrativa de Ángel Rama, Moraña pone de relieve los límites de la permeabilidad de las culturas nacionales y de los alcances de la transitividad. Según la autora, en todos estos conceptos basados en la epistemología de la modernidad, los intercambios culturales se producen del centro a la periferia y se articulan con base en los binomios moderno/vernáculo, centro capital/ regionalismo, etc. Semejante crítica, concluye Moraña, se debería dirigir hasta el archivo criollo de Pascale Casanova y Franco Moretti (La república mundial de las letras), en donde la dicotomía entre lo popular y lo nacional sigue siendo el meollo de las argumentaciones, aunque se busquen categorías fluidas e inestables, así como relacionalidades entre localidad y globalidad; entre

1 A título de ejemplo: "Por un lado, en su obra el paradigma barroco da la cara a los rituales sociales y políticos del Imperio y se apropia de los códigos culturales metropolitanos como una forma simbólica de participación en los universales humanísticos del imperio. Por otro lado, esos intelectuales se articulan a través de sus textos a la realidad tensa y plural de la Colonia a la que ya perciben y expresan como un proceso cultural diferenciado, y utilizan el lenguaje imperial no solo para hablar por sí mismos sino de sí mismos, de sus proyectos, expectativas y frustraciones" (Moraña 239). 
regionalismo y modernización. Los conceptos de intercambio e interrelación ya no son suficientes: este es el reto de los análisis de Moraña en Bourdieu en la periferia (2014). Son negociaciones y reciclajes de material simbólico en espacios que conservan su diferencia; que escapan a los influjos globalizadores.

Contrariamente, los efectos del autoritarismo y de crisis más amplias surgidas en el seno del capitalismo mundial, contribuyeron a la desestabilización de categorías y de la existencia de las culturas nacionales. Algunos autores que son señalados por Moraña porque responden a los nuevos desafíos, merecen mención en este comentario: autores como Alberto Moreiras. Con respecto a El zorro de arriba y el zorro de abajo de Arguedas, Moreiras demuestra el vaciamiento del lenguaje; la fragmentación del mundo ficcional; la mise en abyme de la función autorial; el fracaso de las combinatorias que, desde los centros, imponen impulsos transformadores capaces de desnaturalizar lo local y de enloquecer el mundo de los significados. El suicidio de Arguedas demostraría el fracaso de la modernidad y sus prácticas excluyentes. Resumiendo, Moraña quiere hacer visible la epistemología oculta de la transculturación; esto es, exponer una epistemología de la dependencia, basada en el binomio de centro/periferia, así como sus inversiones, mientras se inclina hacia otras epistemologías basadas en planteamientos de frontera, localidad, agencia, subjetividad colectiva. Según la autora, estas herramientas fundamentan una agencialidad política que responde al desafío de la fase de la globalización actual, definida por los dos momentos antagonistas de extrema integración: la proliferación de marginalidades y la hegemonía, que se originan en contextos globales. Entre los nuevos conceptos, Moraña propone la ecología de saberes de Bonaventura de Sousa Santos; el reconocimiento de alteridades epistémicas y sus correspondientes registros simbólicos, así como la modernidad múltiple de Bolívar Echeverría.

Tengo mis dudas sobre la cartografía histórica que Moraña nos ofrece, basada en un continuo y progresivo desarrollo epistemológico que opone epistemologías actuales a 'la modernidad' y sus fundamentos dicotómicos y dependientes. Si es cierto que los nuevos conceptos subrayan una relacionalidad que va más allá de una relación entendida como un simple intercambio entre culturas excluyentes, entendiendo relacionalidad en el sentido de una conexión primordial de las culturas que cuestiona todas las formas configuradas con base en diferencias, ${ }^{2}$ cabría sin embargo revisar el veredicto que se

2 Se trata de una epistemología en auge hoy en día, basada en la procesualidad de ontologías operativas, tal como las de Gilles Deleuze, Donna Haraway, Bruno Latour, Roberto Esposito y 
emite en contra de conceptos anteriores al turn actual. Me pregunto, pues, si la epistemología de la dependencia que Moraña ve en la base de conceptos de la modernidad no es un esencialismo de los discursos dominantes ni un problema del fenómeno de la modernidad en América Latina. Dicha duda se confirma, entre otros, justamente con base en el modelo histórico discontinuo de Bolívar Echeverría, autor que la misma Moraña menciona entre las nuevas posiciones. Según Echeverría, la modernidad alternativa, que se opone al capitalismo, es común a Europa y América. Su germen se encuentra ya en las operaciones y negociaciones del siglo XI en Europa.

Para no ir tan lejos, me parece urgente la invitación a releer autores que, según Moraña, cabrían en la modernidad esencialista y dependiente. ¿Por qué dejar de reconocer que, también antes del giro actual, y al menos desde José Enrique Rodó, se describieron en América Latina procesos que desafiaron esencialismos y separaciones, provocando el quiebre de binomios geopolíticos o vaciando su centro epistemológico? Mientras que la crítica de la modernidad a la que se inclina Moraña todavía se refiere a la oposición entre centro (Europa) y periferia (América Latina), de la que quiere salir, la modernidad alternativa de Bolívar Echeverría rompe con la polarización entre Europa y América, proponiendo con la 'modernidad' del ethos barroco otro antagonismo que va más allá de las oposiciones territoriales: es el antagonismo que surge entre el capitalismo y la modernidad, capaz de rescatar también en Europa las prácticas culturales del uso y de poner en marcha la búsqueda de una potencialidad que resista al poder violento de superestructuración; búsqueda llevada a cabo por el capitalismo incipiente en Europa ya en los siglos XVI y XVII. ${ }^{3}$

Subrayo, por ende, la necesidad de un análisis de la discontinuidad histórica y de los potenciales de los textos históricos. Tengo dudas acerca de la reciente crítica a La ciudad letrada (1984) de Ángel Rama, efectuada en Bourdieu en la periferia y citada en este volumen. Según Moraña, Ángel Rama no desafía ni desestabiliza la primacía de los parámetros letrados, urbanistas, institucionalizados, patriarcales y occidentalistas. La agencia letrada y el campo escriturario son los espacios en los que se fraguan las estrategias legitimadoras y las prácticas representacionales que la ciudad le-

otros, cuyos fundamentos se encuentran en varias épocas de la historia de la filosofía europea, especialmente, con respecto al temprano siglo Xx, en Whitehead (véase el texto de Vittoria Borsò, "Contingenza del vivente en la era de su producibilità").

3 Véase el texto de Serur Smeke Bolívar Echeverría: Modernidad y resistencias y mi reseña del texto de Borsò de 2015. 
trada ordenará. Aunque ya Rama problematiza lo nacional (burgués, liberal) mostrando el bricolage cultural, dicha teoría, según Moraña, queda influida por la dependencia, como todas las otras acepciones cuyo punto de partida es la modernidad. Ahora bien, Moraña analiza La ciudad letrada a la luz del capital simbólico de la epistemología de los años 80 del siglo XX. Rama, por el contrario, se vale de la crítica del poder (Foucault) para su objetivo histórico; es decir, para describir las relaciones de poder identificadas en la sociedad novohispana. Lo único que se podría objetar sería la poca atención de Rama por el counter power de la 'ciudad escriturienta'; es decir, el counter imaginario que por ejemplo en las escrituras de Sor Juana Inés de la Cruz, de Sigüenza y Góngora, y aun de Bernardo de Balbuena, emerge transversalmente contra el poder, mientras que la élite novohispana manda escribir para construir una nueva cultura urbana (dependiente de la metrópolis). ${ }^{4}$ En lo que concierne a Fernando Ortiz, disiento claramente del diagnóstico de Moraña. Si bien tiene razón con respecto a la dimensión alegórica del texto de Ortiz que contrapone dos entidades diferentes (tabaco y azúcar), a lo largo de la obra las diferencias se diluyen y se trastruecan en las operaciones culturales a las que invita la materialidad concreta de ambos elementos. La procesualidad es el mensaje que emerge de la microestructura; de la estética del texto de Ortiz. Esto me lleva a la pregunta: ${ }_{\mathrm{C}}$ Por qué limitar la modernidad a su sentido como modernización, basada en el proyecto político del progreso eurocéntrico, en el racionalismo científico-técnico y en el liberalismo individualista? Bolívar Echeverría, al que se refiere Moraña, diferencia claramente entre modernización, en este sentido, y modernidad, cuyo potencial resiste a las separaciones capitalistas y las trastrueca. Ambos tipos de procesos son comunes a Europa y América Latina. ¿ $\mathrm{i}$ o se debería entonces focalizar una modernidad crítica del proyecto de la modernización también en América Latina? Justamente el análisis de Alberto Moreiras citado por Moraña, se refiere a autores como Borges, Cortázar, Salvador Elizondo, Tununa Mercado, y demuestra que la escritura del siglo XX hace precisamente vacío el centro que fundamenta las dicotomías de la modernización. Lo mismo se podría constatar también para algunos de los posmodernistas en México, o para los Contemporáneos y muchos otros. ${ }^{5}$ Valdría la pena releer los textos tanto literarios como teóricos y buscar resistencias a nuestros

\footnotetext{
4 Remito a mi análisis en varios ensayos, por ejemplo el de Borsò de 2008.

5 Remito a Eine andere mexikanische Moderne. Die frühen Romanexperimente der Contemporáneos de Björn Goldammer.
} 
propios esencialismos. Buscar las líneas de fuga hacia otra manera de ver nos llevaría a una autoetnografía del eurocentrismo que se oculta en nuestro propio pensar la modernidad, liberándonos del poder (geo)político que subyuga nuestro entender su compleja realidad.

\section{Obras citadas}

Borsò, Vittoria. "La 'ciudad letrada' y la escritura: Repetición e innovación novohispana". Ideas de progreso y decadencia en el Siglo de Oro. Eds. Carmen Rivero Iglesias y Christoph Strosetzki. Bonn: Romanistischer Verlag, 2008. 101-118. Impreso.

Borsò, Vittoria. "Leer a Bolívar Echeverría". iMEX México interdisciplinario 8 (2015). Web. 21 de agosto de 2015.

Borsò, Vittoria. "Contingenza del vivente en la era de su producibilità". (ed.). Contingency, politics, life. Ed. Salvatore Vaccaro. En prensa. 2015. Impreso.

Goldammer, Björn. Eine andere mexikanische Moderne. Die frühen Romanexperimente der Contemporáneos. Frankfurt: Vervuert, 2010. Impreso.

Moraña, Mabel. Viaje al silencio. Exploraciones del discurso barroco. México: UNAM, 1998. Impreso.

Serur Smeke, Raquel. Modernidad y resistencias. México: Era, 2015. Impreso. 